\title{
Comparative study of sonohysterosalpingography with hysterosalpingography for determination of tubal patency in infertile women
}

\author{
Renuka Kumari $^{1 *}$, Priti Bala Sahay ${ }^{2}$
}

\begin{abstract}
${ }^{1}$ Department of Obstetrics and Gynecology, IMS, Banaras Hindu University, Varanasi, Uttar Pradesh, India
${ }^{2}$ Department of Obstetrics and Gynecology, Rajendra Institute of Medical Sciences, Ranchi, Jharkhand, India
\end{abstract}

Received: 01 May 2018

Revised: 12 June 2018

Accepted: 23 June 2018

\section{*Correspondence: \\ Dr. Renuka Kumari, \\ E-mail: drkumarirenuka@gmail.com}

Copyright: (c) the author(s), publisher and licensee Medip Academy. This is an open-access article distributed under the terms of the Creative Commons Attribution Non-Commercial License, which permits unrestricted non-commercial use, distribution, and reproduction in any medium, provided the original work is properly cited.

\section{ABSTRACT}

Background: Ever since the history of mankind, human infertility has been a source of personal misery and social stigma. The aim of this study was to evaluate the tubal factors of infertility, especially the tubal patency by SSG and HSG and study the advantages of both.

Methods: The present work was undertaken in the Department of Obstetrics and Gynecology and Department of Radiodiagnosis of Rajendra Institute of Medical Sciences, Ranchi. 60 patients with primary or secondary infertility attending the OPD were selected over a period of 15 months (July 2008 to September 2009). Inclusion criteria: women of age 20-35 years with regular menstrual cycle whose male partners had no faults. Exclusion criteria: women with PID or other proven causes of infertility. All the patients were subjected to both SSG and HSG (interval period being 1 menstrual cycle) and the results compared in terms of tubal occlusion detection rate, detection of pelvic pathologies and complications of both the procedures.

Results: Out of 60 cases, 70\% (42) were of primary infertility and 30\% (18) were of secondary infertility. History of reproductive tract infections was higher in secondary infertility group (44\%). SSG appeared to be more sensitive in detection of tubal obstruction (35\%) than HSG (30\%), but the difference was statistically insignificant ( $>>0.05$ ). HSG could locate the exact site of tubal obstruction which was not evident in SSG. SSG was more sensitive in detection of associated pelvic pathologies $(\mathrm{p}=0.05)$ like ovarian cyst, endometriosis and fibroid uterus. However, HSG was better in diagnosis of genital tuberculosis. $20 \%$ of patients complained of pelvic pain, bleeding, infection or allergic reaction during or after HSG, while only $7 \%$ of patients reported the same with SSG. Thus, SSG was superior to HSG in this respect $(\mathrm{p}=0.02)$.

Conclusions: SSG, though not a substitute, can be used as an alternative to HSG for assessment of tubal factors of infertility.

Keywords: HSG, Occlusion detection rate, SSG

\section{INTRODUCTION}

Ever since the history of mankind, human infertility has been a source of personal misery and social stigma. Infertility is defined as inability to achieve conception within one or more years of regular unprotected intercourse. Conception depends on fertility potential of both the male and the female partner. Among female factors, tubal factors account for $30-40 \%$ of cases. Assessment of the patency of fallopian tubes therefore is 
considered an essential and preliminary step of any infertility work-up. Our discussion is mainly limited to tubal factors of infertility which are thought to be responsible for $25-35 \%$ of cases of infertility. Patency of fallopian tube is the earliest studied aspect of tubal function.

HSG, though a conventional and standard technique to assess tubal patency, presents a number of potential dangers like exposure to ionizing radiation and anaphylaxis. Laparoscopy with chromotubation, the gold standard method is an invasive one and requires a hospital set up and an expert laparoscopic surgeon too while includes the complications of surgery and anaesthesia.

The development of ultrasound by Kratochwill in 1972 has provided the clinician with the opportunity to visualize the pelvic organs non-invasively. Introduction of transvaginal sonography by Schwiner and Lebonic in 1984 with its better resolution has opened new frontiers in imaging of pelvic organs. Use of sonohysterosalpingography (SSG) in infertility patients to determine tubal patency was first done by Dr. Tina $\mathrm{S}$ Richman (USA).

Sonosalpingography is the ultrasonic visualization of the fallopian tubes using ultrasound echo enhancing agents. Since the fallopian tubes normally are isoechoic, they are not visualized by ultrasound unless pathological or surrounded by fluid. In sonosalpingography, sterile saline is injected transvaginally and the fallopian tubes are focused by abdominal transducer to look for spill of fluid from the fimbrial ends. This transvaginal hydrotubation (using mixture of sterile saline with air) while doing ultrasonography is also known as Sion's test. ${ }^{1}$ Sonosalpingography can also be used to evaluate the endometrium besides the fallopian tubes. Instillation of fluid into the uterine cavity after deflating the foley's balloon improves visualization of submucous fibroids and polyps as well as adhesions (synechae). SSG, offers to us a safe and easy, noninvasive method to look for tubal patency and detect tubal block. In this study, this comparatively new technique, SSG will be compared with the standard, old age technique, HSG in terms of accuracy, efficacy and complications.

The study was undertaken with the aim

- To evaluate tubal patency by SSG and HSG

- To study the advantages and drawbacks of SSG by comparing it with more established technique, the HSG

- To assess whether SSG can be used as a screening test for determination of tubal patency or not.

\section{METHODS}

The work was done in the Department of Obstetric and Gynecology and the Department of Radiology of RIMS,
Ranchi. 60 patients with primary or secondary infertility attending the OPD were selected over a period of 15 months (July 2008 to September 2009).

\section{Inclusion criteria}

Only those women were taken up

- Whose male partners had no faults

- $\quad$ Age between 20-35 years

- Who were regularly menstruating, and all other factors already been ruled out.

\section{Exclusion criteria}

- $\quad$ Ongoing or recent PID

- Age $<20$ or $>35$ years

- Late menses without confirmation of pregnancy

- Patients with other proven causes of infertility.

A proforma was designed for recording of data from history, clinical examination and necessary investigations in each patient. Detailed history pertaining to infertility was taken along with personal and sexual history and treatment history of both the partners. Women were subjected to clinical examination, including detailed general and gynecological examination.

\section{Sonohysteroslpingography (SSG)}

it was carried out in all 60 patients chosen for study. Transabdominal scan was done using a 2-D B- mode real time scanner with a $3.5 \mathrm{Mhz}$ transducer.

\section{Preparation}

SSG was done on D8-D10 of cycle. Bladder must be full. After informed consent, antispasmodic drug was given 30 minutes before the test.

\section{Procedure}

Patient was put in lithotomy position. Sim's speculum inserted into vagina posteriorly and cervix held at anterior lip with volsellum and dilated with a dilator. A Foley's catheter (no. $10 \mathrm{~F}$ ) was inserted transcervically just beyond the internal os and $2-3 \mathrm{ml}$ of saline injected to make it indwelling. Coupling gel was applied liberally over lower abdomen and transducer used to obtain image of uterus with foley's catheter in situ. After that sonographic hydrotubation was done with 20-30 cc of sterile saline with air on left and then right side. Then $150-200 \mathrm{ml}$ of saline infused slowly. The scan will look for collection of fluid in peritoneal cavity and for the "waterfall sign" which indicates tubal patency. In cases of bilateral tubal block, the uterine cavity was seen to distend without subsequent decompression and also reflux of saline and air bubbles could be seen in the stem of Foley's catheter. The catheter was then deflated and 
pulled out. Patients were allowed to rest for a short period of time and sent home with a course of oral antibiotics.

\section{Hysterosalpingography (HSG)}

This test was also done in all the patients and results compared with SSG. It was done on D8-D10 of cycle. One cycle gap was maintained between HSG and SSG.

\section{Preparation}

Inj. Dexamethasone and inj. Chlorpheniramine maleate was kept ready. Antispasmodic was also administered half an hour before the test. Patient asked to void urine before the procedure.

\section{Procedure}

With full aseptic precautions, cervix was gripped with volsellum and a tight fitting plain rubber catheter no. 10 was introduced into uterine cavity just beyond internal os and 2-10 $\mathrm{ml}$ of ionic, monoisomeric, triiodinated, water soluble X-ray contrast dye (urograffin 76\%) was injected into uterine cavity. Exposure was obtained to show peritoneal spillage or tubal obstruction and tubal pathology. If necessary, a repeat film was taken after 10 minutes. At the end of the procedure, catheter taken out, vagina swabbed, and pulse rate of the patient noted. After an observation period of 1hour, patient was discharged with antispasmodics and a course of antibiotics.

\section{RESULTS}

In the present study, the incidence of primary infertility is more than secondary infertility. Primary infertility refers to those patients who have not conceived even once till date despite regular and unprotected intercourse for one or more years. Out of 60 patients chosen in the present study, 42 patients $(70 \%)$ were of primary infertility group.

Secondary infertility refers to those patients who have conceived once or more in the past (irrespective of having live issues or not) but not being able to conceive now despite regular and unprotected intercourse for one or more years. Among 60 patients studied, 18 (30\%) were of secondary infertility.

Table 1: Percentage of primary and secondary infertility.

\begin{tabular}{|l|l|l|}
\hline Type & No. of cases & Percentage \\
\hline Primary & 42 & 70 \\
\hline Secondary & 18 & 30 \\
\hline Total & 60 & 100 \\
\hline
\end{tabular}

Table 2 clearly shows that past history of reproductive tract infections (STD's and genital tuberculosis) is very high in both groups which indicates about the poor sexual hygienic practices among women in our part of country.
Infections are particularly higher in secondary infertility group. This might be due to poor nutritional status of patients in previous pregnancies and lactational period which would have resulted in immunodeficiency and thus proneness to infections. The history of instrumentation and puerperal sepsis is obviously higher in secondary infertility group and this may be the reason for tubal block in such cases.

Table 2: Incidence of genital tract infections and prior pelvic surgeries.

\begin{tabular}{|llllll|} 
Type & $\begin{array}{l}\text { No } \\
\text { history }\end{array}$ & $\begin{array}{l}\text { Past } \\
\text { h/o } \\
\text { THB }\end{array}$ & $\begin{array}{l}\text { H/o } \\
\text { STD }\end{array}$ & $\begin{array}{l}\text { H/o } \\
\text { D/E } \\
\text { and } \\
\text { MTP }\end{array}$ & $\begin{array}{l}\text { Puerperal } \\
\text { sepsis }\end{array}$ \\
\hline $\begin{array}{l}\text { Primary } \\
(\mathrm{n}=42)\end{array}$ & $\begin{array}{l}27 \\
(64 \%)\end{array}$ & $\begin{array}{l}3 \\
(7 \%)\end{array}$ & $\begin{array}{l}12 \\
(29 \%)\end{array}$ & 0 & 0 \\
$\begin{array}{l}\text { Secondary } \\
(\mathrm{n}=18)\end{array}$ & 3 & 1 & 8 & 5 & 1 \\
\hline
\end{tabular}

Table 3 shows that accuracy of both HSG and SSG is more or less the same in assessing tubal status in infertility cases. Of the 60 cases chosen, HSG diagnosed tubal block in 18 cases, while among the same 60 cases, SSG could detect tubal obstruction in 21 cases. Thus, my study shows that SSG is more sensitive than HSG.

However, it was only an incidental finding because on comparison of the two using Chi square test, $\mathrm{p}$ value comes to be 0.65 indicating the result as statistically insignificant. Thus, the table shows that sensitivity of both the tests is almost equal. This implies that SSG is as good as HSG in determining tubal patency in infertile women and can easily replace HSG for preliminary work up of female infertility.

Table 3: Tubal status on HSG and SSG.

\begin{tabular}{|lllll|}
\hline $\begin{array}{l}\text { Condition of } \\
\text { tube }\end{array}$ & HSG $(\mathrm{n}=60)$ & \multicolumn{2}{l|}{ SSG $(\mathrm{n}=60)$} \\
\hline & $\begin{array}{l}\text { No. of } \\
\text { cases }\end{array}$ & $\%$ & $\begin{array}{l}\text { No. of } \\
\text { cases }\end{array}$ & $\%$ \\
\hline Bilateral patent & 42 & 70 & 39 & 65 \\
\hline Bilateral blocked & 9 & 15 & 13 & 21 \\
\hline Right blockade & 4 & 7 & 4 & 7 \\
\hline Left blockade & 5 & 8 & 4 & 7 \\
\hline \begin{tabular}{l}
$P=0.65$ (statistically insignificant) \\
\hline
\end{tabular} & & & \\
\hline
\end{tabular}

Table 4 shows the site of tubal obstruction. The site of block was mostly cornual $(50 \%)$ followed by mid segmental $(33.3 \%)$ and finally distal $(16.7 \%)$. HSG could delineate the exact site of tubal block but SSG gave no idea of the site of tubal obstruction and the region of tube involved. SSG can identify only whether tube is open or not and which side is patent but gives no clue about the segment of the tube involved. The knowledge of exact site of tubal pathology is quite valuable in decision making and planning the management of infertility cases, therefore, HSG is better than SSG in this respect. 
Table 4: Site of tubal obstruction in HSG $(n=120)$.

\begin{tabular}{|lll|}
\hline Site of obstruction & HSG $(n=18)$ & Percentage \\
\hline Cornual & 9 & 50 \\
\hline Mid segment & 6 & 33.3 \\
\hline Distal & 3 & 16.7 \\
\hline
\end{tabular}

Table 5 shows that SSG is definitely better than HSG in detecting associated pelvic pathologies. SSG is more sensitive than HSG in diagnosing pathologies like uterine fibroids (submucous or intramural), ovarian cysts, TO masses and endometriomas as it has added advantage of pelvic sonography.

These unnoticed pathologies may sometimes be the main or contributory causes of female infertility. Using SSG in place of HSG therefore, also tells us about the uterine, ovarian and peritoneal factors of female infertility while determining the tubal patency at the same time. Thus, SSG has an upper hand here. Genital tuberculosis which is important especially in our part of country as a cause of infertility, however, is better diagnosed by HSG than SSG.

Table 5: Diagnosis of associated pelvic pathology by SSG and HSG.

\begin{tabular}{|ll|l|}
\hline Pelvic pathology & SSG $(n=60)$ & HSG $(n=60)$ \\
\hline Hydrosalpinx & 4 & 3 \\
\hline Genital tuberculosis & 1 & 3 \\
\hline Ovarian cyst & 3 & 0 \\
\hline Tuboovarian lump & 4 & 2 \\
\hline Endometriosis & 3 & 0 \\
\hline Uterine fibroid & 4 & 0 \\
\hline Total & 19 & 10 \\
\hline
\end{tabular}

The complications and adverse effects are definitely lower with SSG as compared to HSG as shown in Table 6.

Table 6: Complications during HSG and SSG.

\begin{tabular}{|ll|l|}
\hline Complication & SSG $(\mathbf{n}=60)$ & HSG $(\mathbf{n}=60)$ \\
\hline Pelvic pain & 3 & 5 \\
\hline Bleeding & 1 & 3 \\
\hline Allergic reactions & 0 & 2 \\
\hline Dye intravasation & 0 & 1 \\
\hline Infection & 0 & 1 \\
\hline Total & 4 & 12 \\
\hline
\end{tabular}

Since HSG uses iodine-based dye, the risk of serious allergic reactions and intra/extravasation reactions lies with it. 2 out of 60 patients in my study had severe allergic reactions requiring even ICU care.

More number of patients reported of minor complications like pelvic cramping pain, vaginal bleeding and infections during or after HSG than with SSG. Thus, SSG is more safe and comfortable to patients than HSG.

\section{DISCUSSION}

In the present study, the incidence of primary infertility was more than the secondary one (Table 1). Suttipichate J et al study also revealed that primary infertility is more prevalent than secondary one $(33 / 44) .{ }^{2}$ History of STD's was high in both primary (27\%) and secondary (44\%) infertility cases as shown in Table 2 which indicates about the poor sexual hygienic practices among women in our part of country. Similar was the result of Malinova $\mathrm{M}$ who found that history of pelvic infections were present in $24 \%$ of primary and $39 \%$ of secondary infertility cases. ${ }^{3}$

Out of total 60 cases studied, HSG showed tubal blockade in 18 cases while SSG detected tubal block in 21 in same 60 cases (Table 3). Thus, SSG appeared to be more sensitive in diagnosing tubal block. However, on comparing the results with Chi square test, the difference was found to be statistically insignificant ( $p$ value $=$ $0.65 \%$ ). Present study correlates with results of other studies too as discussed in the table below. It implies that SSG and HSG both are more or less equal in terms of accuracy.

The observations obtained by various other workers regarding the comparison of sonosalpingography with hysterosalpingography for tubal status was as follows

Our findings were quite consistent with the above observations. SSG was found to be highly sensitive and specific in the diagnosis of tubal block and results correlated well with HSG. The discrepancy in the findings may be explained by

- Difference in the viscosities of the media used to assess tubal status

- Time interval between two procedures may improve spontaneously the condition of pelvic organs or may worsen it

- Spasm of the tube or intra-luminal debris may cause differences especially regarding the proximal occlusion

- Technical error and erroneous interpretation of results.

Table 4 shows that HSG could locate the exact site of tubal blockade (majority cornual in my study) which was not possible with SSG (Table 4). El Tabbakh MN also had unilateral or bilateral cornual block in majority (44\%) in his study. ${ }^{7}$ Becaevac $\mathrm{J}$ also concluded that HSG is quite sensitive to detect proximal tubal pathologies $(78 \%) .{ }^{8}$ SSG can identify the side (right/left) of tubal block but cannot comment upon the exact site of tubal obstruction. Thus, HSG has an upper hand here. For diagnosis of associated pelvic pathologies (Table 5) however, SSG definitely was better than HSG (p value $=0.05$ ). Table 5 clearly shows that pathologies like ovarian cysts, endometriomas, uterine fibroids and hydrosalpinx are better detected by SSG and they may 
sometimes be the main underlying or contributory cause of female infertility. Agrawal R et al and Seal SL also found SSG better than HSG for diagnosing associated pelvic pathologies. ${ }^{6,5}$ In assessment of uterine pathologies too, SSG is more accurate as evidenced by Soares et al in their study. ${ }^{9}$ Genital tuberculosis is however better diagnosed by HSG than SSG.

The risk of complications and adverse effects were much lesser with SSG than HSG ( $p$ value $=0.02$ ) as shown in Table 6 so it can be concluded that SSG is more convenient to patients than HSG. Pelvic pain was the most common adverse effect and it may be related to forced dilatation of stenosed cervical os especially in primary infertility cases. ${ }^{10,11}$

\section{CONCLUSION}

HSG though a convenient and standard technique to assess tubal patency, presents a number of potential dangers like exposure to ionizing radiation and anaphylactic reactions. SSG has evolved as a safe, minimally invasive and cost-effective technique with no risk of radiation exposure. It has been found to be equally accurate in demonstrating tubal patency when compared with HSG. Although site of tubal obstruction can be detected by HSG and not SSG, SSG has the added advantages of ultrasound and thus can detect a variety of associated and unnoticed pelvic pathologies. Also, the complication rate is much lower with SSG than HSG.

Thus SSG, though not a substitute, offers certain advantages over HSG and hence can be used in preliminary evaluation of tubal patency in infertile women.

\section{ACKNOWLEDGMENTS}

Authors would like to thank the institute to allow them to carry out this study and to the patients who participated in the study.

Authors would like to express their special gratitude to their guide Prof Priti Bala Sahay, HOD Department of Obstetrics and Gynecology and their co-guide Prof Chandra Mohan, HOD Department of Radiodiagnosis, RIMS, Ranchi who have helped them at every step in this study.

Funding: No funding sources Conflict of interest: None declared

Ethical approval: The study was approved by the Institutional Ethics Committee

\section{REFERENCES}

1. Allahabadia GN. A new test for screening tubal infertility using Sonosalpingography. Int J Gynaecol Obst. 2004;23(4):112-6.

2. Suttipichatte J, Sripramote C, Dejthevaporn T, Virojchaiwong P, Sripramote M. Transvaginal saline sonosalpingography for the assessment of tubal patency. J Obst Gynecol. 2002;14:223-9.

3. Malinova M, Sismondi P. Comparison of Sonosalpingography with Hysterosalpingography for evaluation of tubal patency. Cochrane Ultrasound Obst Gynaecol. 1999;7(1):43-8.

4. Malik B, Patil S. A comparative study of efficacy of Sonosalpingography and Hysterosalpingography to test the tubal patency in all women with primary and secondary infertility. Ultrasound Quarterly. 2014;30(2):129-33.

5. Seal SL, Ghosh D, Saha D. Comparative evaluation of Sonosalpingography, Hysterosalpingography and Laparoscopy for determination of tubal patency. J Obst Gynecol India. 2007;57:158-61.

6. Agrawal R. Role of Hysterosalpingography in evaluation of tubal factors and its comparison with Sonosalpingography. Int. J Reprod Contracept Obst Gynecol. 2016;6(1):121-6.

7. El Tabbakh MN, Slamka P. Transvaginal sonohysterography versus hysterosalpingography and laparoscopy for the assessment of tubal patency. Fertil Steril. 1999;91(3):372-6.

8. Bacevac J, Ganovic R. Diagnostic value of Hysterosalpingography in examination of fallopian tubes in sterile women (abstract). Serbian Arch Whole Med. 2001;129(1)(2):18-21.

9. Soares SR, dos Reis MM, Camargos AF. Diagnostic accuracy of sonohysterography, transvaginal sonography, and hysterosalpingography in patients with uterine cavity diseases. Fertil Steril. 2000;73(2):406-11.

10. Inki P, Palo P, Anttila L. Vaginal Sonosalpingography in the evaluation of tubal patency. Acta Obstet Gynecol Scand. 1998;77:97882.

11. Hajishafiha M, Zobairi T. Diagnostic value of Sonohysterosalpingography in determination of fallopian tube patency as an initial step of routine infertility assessment. J Ultrasound Med. 2009;28(12):1671-7.

Cite this article as: Kumari R, Sahay PB.

Comparative study of sonohysterosalpingography with hysterosalpingography for determination of tubal patency in infertile women. Int J Reprod Contracept Obstet Gynecol 2018;7:3117-21. 